\title{
Intraocular penetration of vancomycin eye drops after application to the medial canthus with closed lids
}

\author{
Yair Alster, Limor Herlin, Moshe Lazar, Anat Loewenstein
}

\begin{abstract}
Aims-To investigate the intraocular penetration of vancomycin eye drops and to compare the conventional method of drop instillation to the lower cul de sac with applying drops to the medial canthus with closed lids.

Methods-This prospective randomised trial evaluated 53 eyes of 53 patients who had undergone extracapsular cataract extraction (ECCE) with intraocular lens implantation. Vancomycin $(50 \mathrm{mg} / \mathrm{ml})$ eye drops were applied to either the lower cul de sac with open lids (conventional method), or to the medial canthus with the patient in a supine position and with closed lids. After paracentesis performed during ECCE, an aqueous humour sample was taken and vancomycin concentration was measured using the TDX vancomycin assay (fluorescence polarisation immunoassay).

Results-Vancomycin concentration in the anterior chamber were above the minimal inhibitory concentration for Gram positive bacteria in the two methods of drop instillation examined (2.04 (SD 1.9) $\mu \mathrm{g} / \mathrm{ml}$ and $1.49(1.1) \mu \mathrm{g} / \mathrm{ml}$ in the open and closed methods, respectively (p $=0.202)$ ).

Conclusions-Vancomycin $(50 \mathrm{mg} / \mathrm{ml})$ reaches therapeutic concentration in the anterior chamber after topical drop application. Comparable concentrations were reached when drops were applied in either the lower cul de sac or to the medial canthus with closed lids. The latter method is proposed as likely to improve patient compliance.

(Br F Ophthalmol 2000;84:300-302)
\end{abstract}

Ophthalmology,

Tel-Aviv Sourasky

Medical Center,

Sackler Faculty of

Medicine, Tel-Aviv

University, Tel-Aviv,

Israel

Y Alster

L Herlin

M Lazar

A Loewenstein

Correspondence to: Yair Alster, MD, Department of Ophthalmology, Tel-Aviv Sourasky Medical Center, 6 Weizmann Street, Tel-Aviv 64239 , Israel

Accepted for publication 25 October 1999 were performed in an animal model. ${ }^{3-5}$ Thus we decided to investigate its penetrance after topical application.
We further evaluated the drug's penetration into the anterior chamber using a novel method of drop application, and to compare it with the conventional method of drop application. ${ }^{6-9}$ The various methods of eye drop instillation are extensively discussed in the ophthalmological literature. These are either mechanical devices designed to help the patient administer the drops, ${ }^{210}$ or various drug delivery systems as reviewed by Sasaki and colleagues, ${ }^{11}$ which aim at improving the drug's penetration through the cornea and thus increase its bioavailability. However, none of these methods has gained wide distribution. The most common method of eye drop instillation is by pulling the lower eyelid down and applying the drop to the lower cul de sac. This technique has been shown to cause as much as $50 \%$ of non-compliance in elderly patients who are treated with eye drops and who are sometimes unable to instil the drug properly due to trembling, limb rigidity, and other handicaps. ${ }^{12}$ After previously demonstrating the equal clinical effect of tropicamide $^{13}$ and cyclopentolate ${ }^{14}$ instilled by means of the closed lid method, we now sought to demonstrate the extent of penetration of vancomycin into the anterior chamber after its application by either the conventional or the closed lid method.

\section{Methods}

SUBJECTS

The study group consisted of patients who underwent extracapsular cataract extraction with an intraocular lens implantation in the department of ophthalmology of the Tel-Aviv Medical Center. A sterile vancomycin solution was prepared by mixing $500 \mathrm{mg}$ vancomycin with $10 \mathrm{ml}$ water for injection to reach a final concentration of $50 \mathrm{mg} / \mathrm{ml}$ which is the common concentration for topical use in ocular infection. All eyes were anaesthetised with a mixture of $2 \mathrm{ml}$ bupivacaine $0.5 \%$ and $2 \mathrm{ml}$ lignocaine (lidocaine) $2 \%$ injected to the peribulbar area approximately 35 minutes before the operation. With the patient in a supine position, a single drop of vancomycin was applied to either the lower cul de sac or to the medial canthus while the lids were closed. The patients were then asked to open their eyes after the drop application. Patients were free to open and close their eye lids as usual. One drop of vancomycin was applied at 5 minutes and one at 15 minutes after the peribulbar anaesthesia. Randomisation was carried out as follows: each consecutive patients was alternatively assigned to either the closed or open method group. 
Before the operation the eye was washed with saline in order to insure that the vancomycin would not remain in the cul de sac and penetrate the eye during aqueous sampling thus giving false readings. At the beginning of the operation, after paracentesis and before capsulorrhexis, an undiluted sample (0.15-0.2 $\mathrm{ml}$ ) of aqueous solution was aspirated. The time lapse between the application of the second drop and aqueous aspiration was recorded. The aqueous sample was sent immediately to the laboratory for measurement of vancomycin concentration. The method used for measuring the drug concentration was the TDX vancomycin assay (fluorescence polarisation immunoassay). Sex, age, and iris colour of all patients was recorded. This protocol was approved by the Helsinki Committee of the Israeli Ministry of Health, and all patients signed an informed consent form.

\section{STATISTICS}

The results are given as mean (SD). The two sample $t$ test was used to compare continuous variables between the groups. The $\chi^{2}$ test was performed on discrete variables between groups. The Pearson correlation coefficient was calculated between age and vancomycin concentration within either group.

\section{Results}

Fifty three eyes of 53 consecutive patients were studied. The vancomycin eye drops were applied in the conventional method in 26 $(49 \%)$ patients, and to the medial canthus while the lids were closed in 27 (51\%). Patients' characteristics are given in Table 1 .

The average concentration of vancomycin in the aqueous humour of the eyes in which the drug was applied in the conventional method was $2.04(1.9) \mu \mathrm{g} / \mathrm{ml}$ compared with a concentration of $1.49(1.1) \mu \mathrm{g} / \mathrm{ml}$ in the group of eyes in which the drug was applied to the medial canthus. No statistically significant difference

Table 1 Patient characteristics

\begin{tabular}{llll}
\hline & Open lids & Closed lids & p Value \\
\hline Mean age (years) (SD) & $67.6(10.8)$ & $70.18(13.4)$ & 0.455 \\
Female & 14 & 12 & 0.49 \\
Male & 12 & 15 & 0.56 \\
Light iris colour & 5 & 7 & \\
Dark iris colour & 21 & 20 & 0.073 \\
Right eye & 14 & 8 & \\
Left eye & 12 & 19 & \\
\hline
\end{tabular}

Table 2 Correlation among sex, iris colour, and eye laterality and the aqueous humour concentration of vancomycin

\begin{tabular}{lll}
\hline & \multicolumn{2}{l}{ Vancomycin concentration $(\mu \mathrm{g} / \mathrm{ml})($ mean $(S D))$} \\
\cline { 2 - 3 } Variable & \multicolumn{1}{c}{ Closed method } & \multicolumn{1}{c}{ Open method } \\
\hline Sex & & \\
$\quad$ Male & $1.37(1.05)(\mathrm{n}=15)$ & $1.81(1.55)(\mathrm{n}=12)$ \\
Female & $1.64(1.19)(\mathrm{n}=12)$ & $2.25(2.2)(\mathrm{n}=14)$ \\
$\mathrm{p}$ Value & 0.548 & 0.563 \\
Iris colour & $1.4(0.92)(\mathrm{n}=20)$ & $2.24(1.99)(\mathrm{n}=21)$ \\
$\quad$ Dark & $1.75(1.57)(\mathrm{n}=7)$ & $1.22(1.35)(\mathrm{n}=5)$ \\
Light & 0.591 & 0.205 \\
$\mathrm{p}$ Value & $2.04(1.46)(\mathrm{n}=8)$ & $2.01(0.34)(\mathrm{n}=14)$ \\
Eye & $1.25(0.85)(\mathrm{n}=19)$ & $2.11(2.4) \mathrm{n}=12)$ \\
$\quad$ Right & 0.189 & 0.902 \\
Left & & \\
$\mathrm{p}$ Value & & \\
\hline
\end{tabular}

was found between the two groups ( $\mathrm{p}=0.202)$. The average time lapse between the application of the second eye drop and the anterior chamber aqueous aspiration was 17.69 (8.15) minutes in the group using the conventional method and 18.07 (6.44) minutes in the closed lid method ( $\mathrm{p}=0.619)$.

Sex, iris colour, and eye laterality were not found to have any significance within either group (Table 2). No correlation was found between age and vancomycin concentration in either method of drug administration ( $p$ $=0.612$ for the closed method and $p=0.289$ for the open method).

\section{Discussion}

The results of our study demonstrate the good penetration of vancomycin into the anterior chamber after topical use in uninflamed human eyes. A concentration above the minimal inhibitory concentration for staphylococcal and streptococcal strains was reached in both application methods. ${ }^{15}$ This study, and the study by Huerva et $a l^{2}$ are, to the best of our knowledge, the only ones to demonstrate the intraocular penetration of vancomycin into the eye after topical use in humans. Such studies provide the scientific background to the wide use of topical vancomycin for treating intraocular infections.

We further showed that instilling vancomycin in the medial canthus while the lids are closed is as effective as instilling the drops in the lower cul de sac in terms of the final concentration of the drug in the anterior chamber. This method is easy to perform in patients who are unable to instil the drug properly due to trembling, limb rigidity, and other handicaps, and does not require the use of commercial instruments. The results of this study support the results of previous studies performed, in which the two methods were shown to have an equal effect using different drugs. ${ }^{13} 141617$ (equivalent findings were reported by Hug and Cibis, presented at the annual meeting of the American Academy of Pediatric Ophthalmology and Strabismus, Orlando, Florida, 1995).

The results of our study which show equal penetration of vancomycin to the anterior chamber after its application by either method give a measurable credibility to the equal clinical effect as had been demonstrated earlier by us and others with various drugs.

Accordingly, we advocate the use of vancomycin eye drops in intraocular anterior segment infections when indicated. It should be noted that application of drugs to the eye is not usually done after peribulbar anaesthesia. This may cause reduced blinking and thus disruption of the normal tear flow, and may also damage corneal integrity. On the other hand, we would expect better penetration of the drug to an inflamed eye. Thus, the extrapolation of the results of this study should be considered in these respects. The results do, however, compare the two methods in the same clinical setting and are supported, as has been mentioned previously, by other studies. Although we assume the suggested method is 
more comfortable to the patients, this has only been demonstrated in our study on a paediatric population and with cyclopentolate, ${ }^{14}$ and further studies are needed in order to verify this claim.

Application of eye drops to the medial canthus raises the question of whether bacteria present on the skin might be transferred to the ocular surface. Although it has been demonstrated that the amount and diversity of the bacterial flora on the lids and the conjunctiva are essentially the same, ${ }^{18}$ we hesitate to recommend this method in immunologically compromised patients or in an eye that has recently undergone an operation until this aspect has been investigated in greater depth.

For those patients who need to take eye drops daily, impaired vision and limited hand motion might hinder the usual method of drug application and reduce patients' compliance. Thus, the method of eye drop application to the medial canthus can be useful in achieving better compliance in disabled adults who need long term treatment.

We thank Esther Eshkol who provided editorial assistance.

1 Endophthalmitis Vitrectomy Study Group. Results of The Endophthalmitis Vitrectomy Study. A randomized trial of immediate vitrectomy and of intravenous antibiotics for the treatment of postoperative bacterial endophthalmitis. Arch Ophthalmol 1995;113:1479-99.

2 Huerva V, Sinus MA, del Buey JA, et al. Levels of vancomycin in aqueous humor after topical eye drops administration. F Ocul Pharmacol 1993;9:167-70.
3 Choi TB, Lee DA. Transscleral and transcorneal iontophoresis of vancomycin in rabbit eyes. $f$ Ocul Pharmacol 1988;4:153-64.

4 Phinney RB, Schwartz SD, Lee DA, et al. Collagen-shield delivery of gentamycin and vancomycin. Arch Ophthalmol 1988;106:1599-604

5 Pryor JG, Apt L, Leopold IH. Intraocular penetration of vancomycin. Arch Ophthalmol 1962;67:608-11.

6 Lebensohn JE. The eyedrop. Am f Ophthalmol 1974;77: 600-2.

7 Letocha CE. Methods of self administration of eyedrops. Ann Ophthalmol 1985;17:768-9.

8 Mishima S. Clinical pharmacokinetics of the eye: Proctor lecture. Invest Ophthalmol Vis Sci 1981;21:504-41.

9 Zimmerman TJ, Ziegler LP. Successful topical medication: methodology as well as diligence. Ann Ophthalmol 1984;16: 109.

10 Halberg GP, Kelly SE, Morrone M. Drug delivery systems for topical ophthalmic medication. Ann Ophthalmol 1975; 7:1199-209.

11 Sasaki H, Yamamura K, Mukai T, et al. Enhancement of ocular drug penetration. Crit Rev Ther Drug Carrier Syst 1999;16:85-146.

12 Winfield AJ, Jessiman D, Williams A, et al. A study of the causes of non-compliance by patients prescribed eyedrops. Br F Ophthalmol 1990;74:477-80.

13 Loewenstein A, Bolocinic S, Goldstein M, et al. Application of eye drops to the medial canthus. Graefes Arch Clin Exp Ophthalmol 1994;232:680-2.

14 Stolovitch C, Alster Y, Loewenstein A, et al. Application of cyclopentolate $1 \%$ to the medial canthus in children. $f$ Pediatric Ophthalmol Strabismus 1998;35:182-4

15 Kapusnik-Uner JE, Sande MA, Chambres HF. Chapter 47 In: Goodman LS, Gilman AG, Hardman JG, Limbird LE, eds. Goodman and Gilman's the pharmacological basis of therapeutics. 9th ed. New York: McGraw-Hill, 1996: 1144-6.

16 Smith SE. Eye drop instillation for reluctant children. $\mathrm{Br} \mathcal{F}$ Ophthalmol 11991;75:480-1.

17 Sharp J, Wallace T, Hanna C. Mydriasis using spray on the closed eye. $\mathcal{F}$ Pediatr Ophthalmol Strabismus 1975;12: $120-2$.

18 Locatcher-Khorazo D, Seegal BC. The bacterial flora of the healthy eye. In: Locatcher-Khorazo D, Seegal BC, eds. Microbiology of the eye. St Louis: CV Mosby, 1972:13-23. 